\title{
Correlation of the TCF7L2 (rs7903146) polymorphism with an enhanced risk of type 2 diabetes mellitus: a meta-analysis
}

\author{
Y. Guan, L.H. Yan, X.Y. Liu, X.Y. Zhu, S.Z. Wang and L.M. Chen \\ Key Laboratory of Hormones and Development (Ministry of Health), \\ Tianjin Key Laboratory of Metabolic Diseases, \\ Tianjin Metabolic Diseases Hospital \& Tianjin Institute of Endocrinology, \\ Tianjin Medical University, Tianjin, China \\ Corresponding author: L.M. Chen \\ E-mail: chenlmingtj@yeah.net
}

Genet. Mol. Res. 15 (3): gmr.15037969

Received December 16, 2015

Accepted January 21, 2016

Published August 26, 2016

DOI http://dx.doi.org/10.4238/gmr.15037969

Copyright (C) 2016 The Authors. This is an open-access article distributed under the terms of the Creative Commons Attribution ShareAlike (CC BY-SA) 4.0 License.

\begin{abstract}
Increasing evidence has demonstrated that a transcription factor 7-like 2 (TCF7L2) polymorphism (rs7903146) is significantly associated with type 2 diabetes mellitus (T2DM); however, limited sample size and variance of ethnicity in the studies investigating this association have led to conflicting reports regarding its role. Therefore, a comprehensive meta-analysis was conducted to quantitatively assess the association between the TCF7L2 polymorphism (rs7903146) and T2DM including published case-control studies in global populations. We searched the PubMed, EMbase, CNKI, and Wanfang databases for publications that studied correlation between TCF7L2 polymorphism (rs7903146) and risk of T2DM. Thirty-six studies from 30 eligible papers were identified. After data extraction and reference quality assessment, summary odds ratio and $95 \%$ confidence intervals $(95 \% \mathrm{CI})$
\end{abstract}

Genetics and Molecular Research 15 (3): gmr.15037969 
of the TCF7L2 (rs7903146) polymorphism were calculated and combined using the fixed-effect model. Hardy-Weinberg equilibrium was evaluated to determine selection bias of the control subjects. Heterogeneity among studies was examined using the Q-test and the $\mathrm{I}^{2}$ test. Publication bias in studies was assessed using Begg's plots and the Egger test. The results showed that the rs7903146 T allele of the TCF7L2 gene was positively correlated with an enhanced risk of T2DM in the allelic, heterozygote, homozygote, dominant, and recessive models, with odds ratios of 1.35 ( $\mathrm{T}$ vs $\mathrm{C}, 95 \% \mathrm{CI}=1.31-1.39), 1.32$ (CT vs $\mathrm{CC}, 95 \% \mathrm{CI}=1.27-1.38), 1.74$ ( $\mathrm{TT}$ vs $\mathrm{CC}, 95 \% \mathrm{CI}=1.63-1.87), 1.40$ $(\mathrm{TT}+\mathrm{CT}$ vs $\mathrm{CC}, 95 \% \mathrm{CI}=1.35-1.46)$, and $1.59(\mathrm{TT}$ vs $\mathrm{CT}+\mathrm{CC}, 95 \% \mathrm{CI}$ $=1.49-1.69$ ), respectively. No obvious publication bias was observed using the Egger linear test.

Key words: Meta-analysis; Polymorphism; Transcription factor 7-like 2; Type 2 diabetes

\section{INTRODUCTION}

Type 2 diabetes mellitus (T2DM) is a metabolic disease characterized by hyperglycemia caused by progressive insulin deficiency with insulin resistance and is a large health burden worldwide (Sun et al., 2015). The incidence of T2DM is increasing significantly, with 90 million individuals with diabetes in China in 2011, and shows no signs of alleviation. Individuals with T2DM often suffer serious systematic complications, including nephropathy, retinopathy, neuropathy, and accelerated cardiovascular disease progression (Grant et al., 2006). Therefore, diabetes and its complications impose economic pressure on individuals, families, and society, and it is imperative that the detailed mechanisms of diabetes genesis are elucidated and the high-risk populations are identified.

Although the mechanism of T2DM is not completely understood, genetic variants play a critical role in the pathophysiology and etiology of the disease (Risérus et al., 2009; $\mathrm{Wu}, 2015)$. The transcription factor 7-like 2 (TCF7L2) gene, which is located on chromosome 10q25.3, encodes a high mobility group box-containing transcription factor that plays a central role in the Wnt pathway and in the regulation of beta-cell function (Wagner et al., 2014). TCF7L2 is considered a major susceptibility gene of T2DM (Grant et al., 2006; Pagán et al., 2014). The TCF7L2 protein is associated with blood glucose homeostasis. Increasing evidence suggests that TCF7L2 polymorphisms were associated with T2DM in different ethnic populations and that it is one of the most significant gene loci for T2DM susceptibility (Bodhini et al., 2007; Xia et al., 2015). Among the several single nucleotide polymorphisms of TCF7L2, variant rs7903146 (IVS3C/T) showed the strongest correlation with the risk of T2DM in previous studies (Grant et al., 2006; Saxena et al., 2006; Cauchi and Froguel, 2008). Therefore, studies of TCF $7 L 2$ genetic polymorphisms will increase the understanding of the mechanism of T2DM and facilitate the screening for individuals at a relatively high risk of T2DM (Cauchi and Froguel, 2008). However, previous studies show conflicting results and clear variations based on ethnicity and regions (Miyake et al., 2008; Ren et al., 2008; Yu et al., 2010). Given their limited sample sizes, the previous studies were underpowered for evaluating the association of the TCF7L2 (rs7903146, IVS3C/T) polymorphism with the susceptibility to

Genetics and Molecular Research 15 (3): gmr.15037969 
T2DM, and thus combined data regarding this single nucleotide polymorphism can be used to assess the global impact of the TCF7L2 polymorphisms on T2DM.

Therefore, we performed this comprehensive meta-analysis to investigate the TCF7L2 (rs7903146, IVS3C/T) polymorphism in previous case-control studies and to assess the association between this polymorphism and T2DM. The results of previous studies were combined to evaluate the strength of this association.

\section{MATERIAL AND METHODS}

\section{Identification and eligibility of relevant studies}

We searched the PubMed, EMbase, CNKI, and Wanfang databases for publications that studied the correlation between the TCF7L2 polymorphism (rs7903146) and the risk of T2DM from January 2006, when the relationship between TCF7L2 and T2DM was first reported (Grant et al., 2006) to April 30, 2014. The combination of MeSH terms and key words, including "transcription factor 7-like 2", "transcription factor 7-like 2 polymorphism", "TCF7L2", "TCF7L2 gene polymorphism", "diabetes", "type 2 diabetes", "diabetes 2", "type 2 diabetes mellitus", "T2DM", and "T2D", was used in our search strategy. In addition, the references of all retrieved publications were screened for additional studies, and then the "Related Articles" option of PubMed was reviewed for potentially relevant publications. The search was conducted independently by two investigators. We selected publications if they met the following inclusion criteria: 1) the publication studied the association between the TCF7L2 polymorphism (rs7903146, IVS3C/T) and T2DM; 2) there were sufficient data for each allele and genotype to recalculate the odds ratio (OR) and $95 \%$ confidence interval $(95 \% \mathrm{CI}) ; 3)$ the publication used a population-based design; and 4) the control group of the study met Hardy-Weinberg equilibrium (HWE) $(\mathrm{P}>0.05)$. Studies were excluded based on the following criteria: 1) studies without control subjects; 2) studies including overlapping data; 3) studies that were reviews or meta-analysis; and 4) studies where the average age of cases and controls were less than 25 years (in an attempt to obviate patients with type 1 diabetes). Patients with T2DM were diagnosed and confirmed based on the World Health Organization criteria in 1999 and if they were taking anti-diabetic treatments (Alberti and Zimmet, 1998). Normoglycemic subjects were defined as the control group and had plasma glucose levels lower than $7.8 \mathrm{mM}$ and fasting glucose levels lower than $6.1 \mathrm{mM}$ in the 2-h oral glucose tolerance test.

\section{Data collection}

Two experienced investigators independently conducted the data extraction. Discrepancies were resolved through discussion. The following detailed information was collected from each publication: name of the first author and the publication year, region, design, ethnicity, number of cases and controls, genotyping method, genotype frequencies, and $P$ value of HWE in control subjects. We recalculated the P value of the HWE test according to the reported genotype frequencies if the studies did not show HWE. To enhance the statistical power, we performed meta-analysis for the TCF7L2 polymorphism (rs7903146) with reported data extracted from more than 10 independent studies.

Genetics and Molecular Research 15 (3): gmr.15037969 


\section{Statistical analysis}

The statistical STATA 12.0 software was used to conduct the meta-analysis based on genotype frequencies. The P value of HWE for control subjects was evaluated by utilizing the chi-squared test. There was no deviation from HWE if the $P$ value $>0.05$. The pooled ORs and $95 \%$ CIs were used to measure the strength of the association of the TCF7L2 polymorphism (rs7903146, IVS3C/T) with the risk of T2DM in all genetic models. Heterogeneity among studies was examined using the Q-test and the $\mathrm{I}^{2}$ test. According to Cochrane reviewer's handbook, the heterogeneity among studies with $\mathrm{I}^{2}<50 \%$ and $\mathrm{P}>0.05$ were accepted (Ling et al., 2004). There was no obvious heterogeneity among studies, so the fixed-effect model was used to perform meta-analysis (Mantel and Haenszel, 1959). Otherwise, a random-effect model was used to calculate the pooled OR and 95\%CI (Midgette et al., 1994). Subgroup analyses were conducted by ethnicity (Asian or Caucasians) for each model. Begg's funnel plot and the Egger linear test were used to evaluate publication bias. A symmetric plot or a $\mathrm{P}$ value of the Egger test more than 0.05 indicated no obvious publication bias (Harbord et al., 2006). The stability and reliability of the meta-analysis were assessed using sensitivity analysis by omitting one study at a time, and thus the impact of each study on the overall summary results was evaluated.

\section{RESULTS}

\section{Study characteristics}

We first identified 352 potentially relevant publications using the search strategy. After excluding the studies that did not present useful data related to the meta-analysis or did not meet the inclusion criteria, 36 case-control studies from 33 eligible papers were obtained, including 26,498 case and 37,282 control subjects. The search strategy is shown as a flow chart in Figure 1. The detailed characteristics of the studies, such as the first author's name, year of publication, ethnicity, country, genotyping method, design, total numbers, and case and control subjects are presented in Table 1. Eight studies used hospital-based controls, whereas the remaining studies used population-based controls. Blood samples were collected for genotyping. The scores of quality assessment for each included publication were more than 26 (moderate-high quality) (da Costa et al., 2011). The P value of HWE for control groups and genotype frequencies of the TCF7L2 gene polymorphism (rs7903146, IVS3C/T) were recalculated and extracted from the eligible studies and are presented in Table 2. All included studies were in HWE $(\mathrm{P}>0.05)$.

\section{Quantitative analysis}

Thirty-three eligible studies including 26,498 type 2 diabetic subjects and 37,282 control subjects were evaluated for the association between the TCF7L2 rs7903146 polymorphism and T2DM. The comprehensive results for these 33 studies are shown in Table 2 . We observed that the TCF7L2 rs7903146 T allele was significantly correlated with an enhanced susceptibility to T2DM under the allelic (Figure 2), heterozygous (Figure 3), homozygous (Figure 4), dominant (Figure 5), and recessive (Figure 6) models. Since there was no heterogeneity among studies, the fixed-effect model was used for analysis.

Genetics and Molecular Research 15 (3): gmr.15037969 


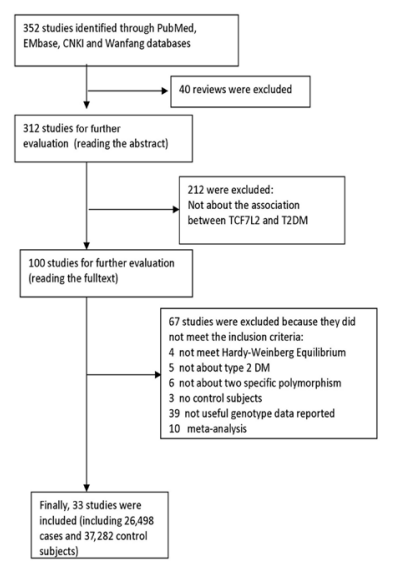

Figure 1. Flow chart of included and excluded studies.

\section{Table 1. Characteristics of studies included in the meta-analysis.}

\begin{tabular}{|c|c|c|c|c|c|c|}
\hline Authors & Country & Ethnicity & Case & Control & Genotyping & Design \\
\hline Groves et al. (2006) & UK & Caucasian & 2001 & 2476 & KASPar & PB \\
\hline Bodhini et al. (2007) & India & Caucasian & 1031 & 1038 & PCR-RFLP & HB \\
\hline Chandak et al. (2007) & India & Caucasian & 955 & 399 & PCR sequencing & PB \\
\hline De Silva et al. (2007) & UK & Caucasian & 487 & 300 & KASPar & PB \\
\hline Hayashi et al. (2007) & Japan & Asian & 1619 & 1067 & TaqMan & PB \\
\hline Horikoshi et al. (2007) & Japan & Asian & 1174 & 823 & PCR sequencing & $\mathrm{PB}$ \\
\hline Humphries et al. (2006) & UK & Caucasian & 224 & 2493 & TaqMan & PB \\
\hline Kimber et al. (2007) & UK & Caucasian & 3225 & 3291 & TaqMan & PB \\
\hline Marzi et al. (2007) & Germany & Caucasian & 651 & 1641 & MALDI-TOF & PB \\
\hline Mayans et al. (2007) & Sweden & Caucasian & 824 & 820 & TaqMan & PB \\
\hline Parra et al. (2007) & Mexico & Others & 283 & 271 & PCR-RFLP & $\mathrm{PB}$ \\
\hline van Hateren et al. (2015) & Netherlands & Caucasian & 496 & 907 & TaqMan & PB \\
\hline Alsmadi et al. (2008) & Kingdom of Saudi Arabia & Others & 522 & 346 & PCR sequencing & PB \\
\hline Kunika et al. (2008) & Japan & Asian & 1422 & 1423 & TaqMan & $\mathrm{PB}$ \\
\hline Marquezine et al. (2007) & Brazil & Others & 112 & 1295 & PCR-RFLP & PB \\
\hline Miyake et al. (2008a) & Japan & Asian & 465 & 323 & TaqMan & HB \\
\hline Miyake et al. (2008b) & Japan & Asian & 539 & 554 & TaqMan & HB \\
\hline Miyake et al. (2008c) & Japan & Asian & 1150 & 957 & TaqMan & HB \\
\hline Rees et al. (2008) & UK & Caucasian & 828 & 432 & TaqMan & $\mathrm{HB}$ \\
\hline Sanghera et al. (2008) & India & Caucasian & 544 & 537 & TaqMan & PB \\
\hline Ezzidi et al. (2009) & Tunisia & Others & 863 & 511 & TaqMan & PB \\
\hline Yan et al. (2009) & USA & Others & 485 & 2242 & TaqMan & $\mathrm{PB}$ \\
\hline Yan et al. (2008) & USA & Caucasian & 925 & 8379 & TaqMan & PB \\
\hline Chen et al. (2010) & China & Asian & 258 & 239 & PCR-RFLP & PB \\
\hline Ereqat et al. (2009) & Palestine & Others & 219 & 114 & PCR-RFLP & PB \\
\hline Gupta et al. (2012) & India & Caucasian & 195 & 161 & TaqMan & PB \\
\hline Lin et al. (2010) & China & Others & 1529 & 1439 & SNapShot & $\mathrm{PB}$ \\
\hline Barra et al. (2012) & Brazil & Others & 113 & 139 & PCR & HB \\
\hline Buraczynska et al. (2012) & Poland & Caucasian & 980 & 924 & PCR-RFLP & HB \\
\hline Feng et al. (2012) & China & Asian & 193 & 186 & PCR & $\mathrm{PB}$ \\
\hline Liu et al. (2012) & China & Asian & 458 & 186 & TaqMan & PB \\
\hline Palizban et al. (2012) & Iran & Caucasian & 110 & 80 & PCR-RFLP & PB \\
\hline Qiao et al. (2012) & China & Asian & 516 & 557 & PCR & PB \\
\hline Tangjittipokin et al. (2012) & Thailand & Asian & 201 & 205 & TaqMan & PB \\
\hline Zheng et al. (2012b) & China & Asian & 227 & 152 & MALDI-TOF MS & PB \\
\hline Danquah et al. (2012) & Ghana & Caucasian & 674 & 375 & PCR-RFLP & $\mathrm{HB}$ \\
\hline
\end{tabular}

KASPar: KBiosciences using a fluorescence-based competitive allele-specific assay. MALDI-TOF MS: matrixassisted laser desorption ionization-time of flight mass spectrometry. PCR-RFLP: polymerase chain reactionrestriction fragment length polymorphism; PB: population-based study; HB: hospital-based study.

Genetics and Molecular Research 15 (3): gmr.15037969 
Table 2. Distribution of the TCF7L2 gene polymorphism (rs7903146) in T2DM.

\begin{tabular}{|c|c|c|c|c|c|c|c|c|c|c|c|}
\hline Authors & $\mathrm{CC}$ & CT & TT & $\mathrm{T}$ & $\mathrm{C}$ & $\mathrm{CC}$ & CT & TT & $\mathrm{T}$ & $\mathrm{C}$ & P of HWE \\
\hline Groves et al. (2006) & 771 & 960 & 270 & 1500 & 2502 & 1175 & 1084 & 217 & 1518 & 3434 & 0.14 \\
\hline Bodhini et al. (2007) & 462 & 455 & 114 & 683 & 1379 & 555 & 391 & 92 & 575 & 1501 & 0.06 \\
\hline Chandak et al. (2007) & 391 & 423 & 141 & 705 & 1205 & 205 & 160 & 34 & 228 & 570 & 0.73 \\
\hline De Silva et al. (2007) & 209 & 208 & 70 & 348 & 626 & 148 & 120 & 32 & 184 & 416 & 0.30 \\
\hline Hayashi et al. (2007) & 1450 & 165 & 4 & 173 & 3065 & 980 & 85 & 2 & 89 & 2045 & 0.91 \\
\hline Horikoshi et al. (2007) & 1051 & 119 & 4 & 127 & 2221 & 770 & 51 & 2 & 55 & 1591 & 0.16 \\
\hline Humphries et al. (2006) & 91 & 111 & 22 & 155 & 293 & 1295 & 1001 & 197 & 1395 & 3591 & 0.85 \\
\hline Kimber et al. (2007) & 1405 & 1459 & 361 & 2181 & 4269 & 1714 & 1329 & 248 & 1825 & 4757 & 0.66 \\
\hline$\overline{\text { Marzi et al. (2007) }}$ & 282 & 296 & 73 & 442 & 860 & 842 & 678 & 121 & 920 & 2362 & 0.33 \\
\hline Mayans et al. (2007) & 452 & 318 & 54 & 426 & 1222 & 532 & 253 & 35 & 323 & 1317 & 0.48 \\
\hline Parra et al. (2007) & 185 & 87 & 11 & 109 & 457 & 191 & 73 & 7 & 87 & 455 & 0.99 \\
\hline van Hateren et al. (2015) & 203 & 221 & 72 & 365 & 627 & 459 & 365 & 83 & 531 & 1283 & 0.40 \\
\hline Alsmadi et al. (2008) & 179 & 253 & 90 & 433 & 611 & 125 & 162 & 59 & 280 & 412 & 0.60 \\
\hline Kunika et al. (2008) & 1246 & 171 & 5 & 181 & 2663 & 1309 & 111 & 3 & 117 & 2729 & 0.69 \\
\hline Marquezine et al. (2007) & 45 & 54 & 13 & 80 & 144 & 564 & 603 & 128 & 859 & 1731 & 0.07 \\
\hline Miyake et al. (2008a) & 426 & 38 & 1 & 40 & 890 & 305 & 18 & 0 & 18 & 628 & 0.61 \\
\hline Miyake et al. (2008b) & 475 & 63 & 1 & 65 & 1013 & 512 & 42 & 0 & 42 & 1066 & 0.35 \\
\hline Miyake et al. (2008c) & 1020 & 127 & 3 & 133 & 2167 & 879 & 77 & 1 & 79 & 1835 & 0.61 \\
\hline Rees et al. (2008) & 352 & 360 & 116 & 592 & 1064 & 222 & 166 & 44 & 254 & 610 & 0.12 \\
\hline Sanghera et al. (2008) & 191 & 261 & 92 & 445 & 643 & 236 & 224 & 77 & 378 & 696 & 0.05 \\
\hline Ezzidi et al. (2009) & 250 & 396 & 217 & 830 & 896 & 181 & 235 & 95 & 425 & 597 & 0.23 \\
\hline Yan et al. (2009) & 225 & 212 & 48 & 308 & 662 & 1156 & 921 & 165 & 1251 & 3233 & 0.32 \\
\hline Yan et al. (2008) & 432 & 392 & 101 & 594 & 1256 & 4295 & 3391 & 693 & 4777 & 11981 & 0.52 \\
\hline Chen et al. (2010) & 192 & 57 & 9 & 75 & 441 & 202 & 33 & 4 & 41 & 437 & 0.06 \\
\hline Ereqat et al. (2009) & 55 & 110 & 54 & 218 & 220 & 55 & 51 & 8 & 67 & 161 & 0.41 \\
\hline Gupta et al. (2012) & 55 & 96 & 44 & 184 & 206 & 62 & 78 & 21 & 120 & 202 & 0.65 \\
\hline Lin et al. (2010) & 1348 & 178 & 3 & 184 & 2874 & 1328 & 107 & 4 & 115 & 2763 & 0.24 \\
\hline Barra et al. (2012) & 49 & 47 & 17 & 81 & 145 & 70 & 63 & 6 & 75 & 203 & 0.08 \\
\hline Buraczynska et al. (2012) & 416 & 407 & 157 & 721 & 1239 & 490 & 360 & 74 & 508 & 1340 & 0.49 \\
\hline Feng et al. (2012) & 89 & 81 & 23 & 127 & 259 & 100 & 74 & 12 & 98 & 274 & 0.73 \\
\hline Liu et al. (2012) & 422 & 35 & 1 & 37 & 879 & 172 & 14 & 0 & 14 & 358 & 0.59 \\
\hline Palizban et al. (2012) & 32 & 52 & 26 & 104 & 116 & 32 & 41 & 7 & 55 & 105 & 0.22 \\
\hline Qiao et al. (2012) & 107 & 132 & 277 & 686 & 346 & 101 & 264 & 192 & 648 & 466 & 0.54 \\
\hline Tangjittipokin et al. (2012) & 172 & 25 & 4 & 33 & 369 & 183 & 21 & 1 & 23 & 387 & 0.64 \\
\hline Zheng et al. (2012b) & 202 & 24 & 1 & 26 & 428 & 139 & 13 & 0 & 13 & 291 & 0.58 \\
\hline Danquah et al. (2012) & 273 & 323 & 78 & 479 & 869 & 182 & 165 & 28 & 221 & 529 & 0.26 \\
\hline
\end{tabular}

HWE $=$ Hardy-Weinberg equilibrium.

The pooled OR for T2DM risk was 1.35 for allelic comparison $(\mathrm{T} v s \mathrm{C}, 95 \% \mathrm{CI}=$ $\left.1.31-1.39, \mathrm{P}=0.000, \mathrm{I}^{2}=22.1 \%, \mathrm{P}_{\text {heterogeneity }}=0.121\right), 1.32$ for heterozygous comparison $(\mathrm{CT}$ vs $\left.\mathrm{CC}, 95 \% \mathrm{CI}=1.27-1.38, \mathrm{P}=0.000, \mathrm{I}^{2}=43.5 \%, \mathrm{P}_{\text {heterogeneity }}=0.003\right), 1.74$ for homozygous comparison (TT vs CC, $\left.95 \% \mathrm{CI}=1.63-1.87, \mathrm{P}=0.000, \mathrm{I}^{2}=15.3 \%, \mathrm{P}_{\text {heterogeneity }}=0.213\right), 1.40$ for dominant comparison $\left(\mathrm{TT}+\mathrm{CT}\right.$ vs $\mathrm{CC}, 95 \% \mathrm{CI}=1.35-1.46, \mathrm{P}=0.000, \mathrm{I}^{2}=15.0 \%, \mathrm{P}$ $=0.218), 1.59$ for recessive comparison $\left(\mathrm{TT} v_{s} \mathrm{CT}+\mathrm{CC}, 95 \% \mathrm{CI}=1.49-1.69, \mathrm{P}=0.000, \mathrm{I}^{2} \stackrel{\text { h }}{=}\right.$ $19.8 \%, \mathrm{P}_{\text {heterogeneity }}=0.150$ ). Since no obvious heterogeneity among studies was detected, the fixed-effect model was used to calculate the pooled OR.

\section{Publication bias diagnostics}

In order to evaluate the publication bias of the included studies, Begger's funnel plot and the Egger linear test were used. As demonstrated in Figure 7A for the heterozygous model (CT vs $\mathrm{CC}, \mathrm{z}=0.40, \mathrm{P}=0.693$ ), Figure $7 \mathrm{~B}$ for the homozygous model (TT vs $\mathrm{CC}, \mathrm{z}=0.89, \mathrm{P}$ $=0.376)$, Figure $7 \mathrm{C}$ for the dominant model $\left(\mathrm{TT}+\mathrm{CT} v_{s} \mathrm{CC}, \mathrm{z}=-0.01 \mathrm{P},=1.000\right)$, and Figure 7D for the recessive model (TT $v s \mathrm{CT}+\mathrm{CC}, \mathrm{z}=1.10, \mathrm{P}=0.270$ ), the funnel plots showed no significant asymmetry in all genetic models. 
TCF7L2 polymorphism and risk of T2DM

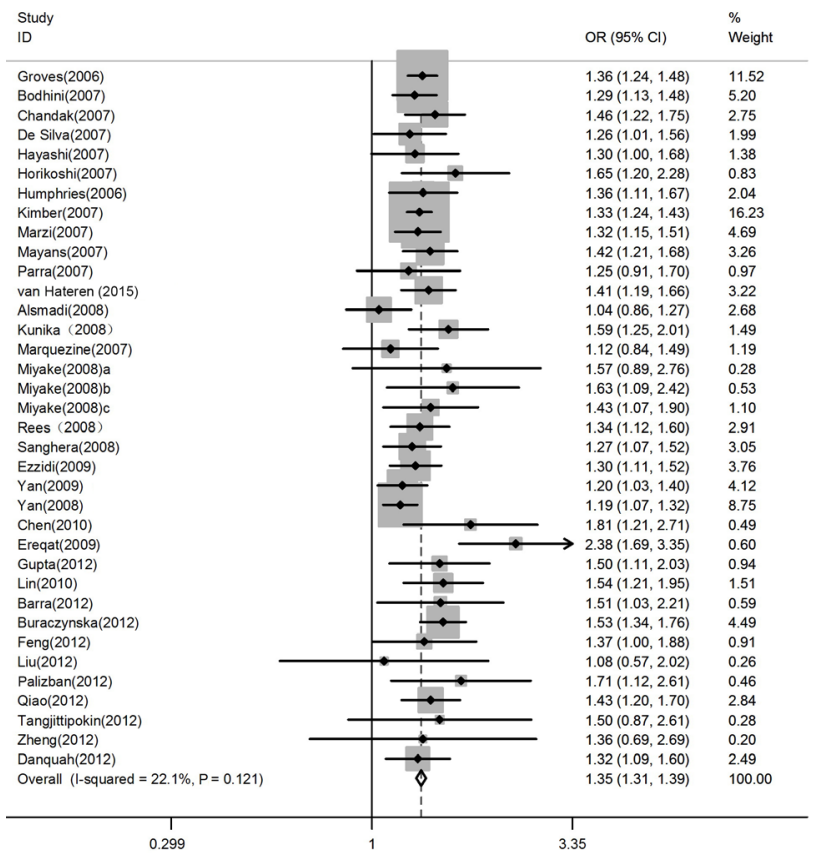

Figure 2. Forest plot showing association between the TCF7L2 rs7903146 polymorphism and T2DM risk under allelic model ( $\mathrm{T} v s \mathrm{C})$.

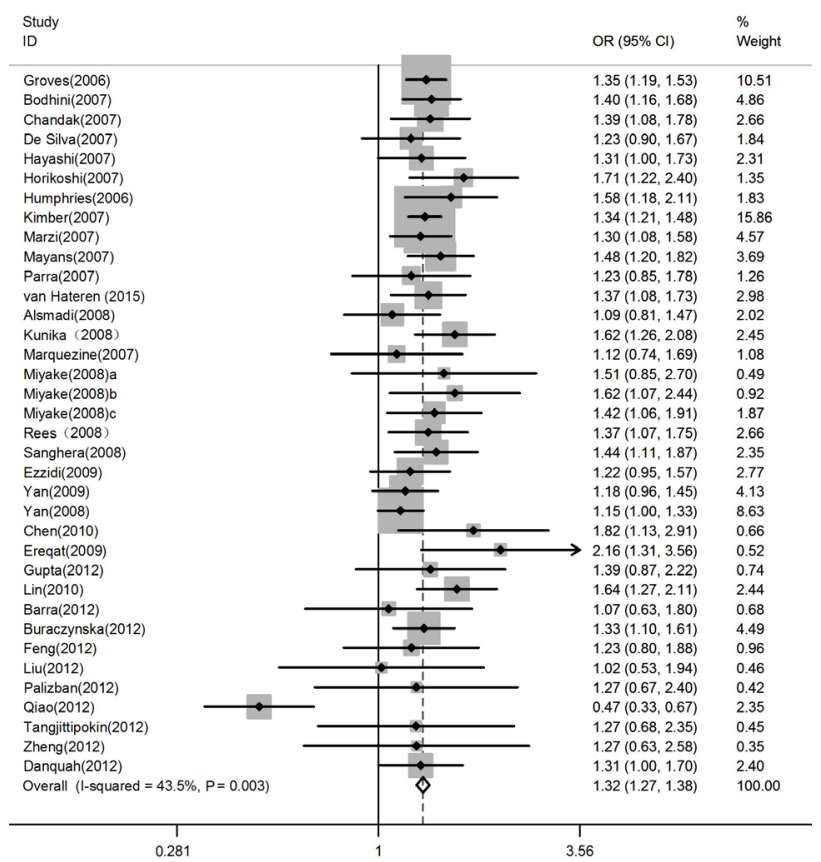

Figure 3. Forest plot showing association between the TCF7L2 rs7903146 polymorphism and T2DM risk under heterozygous model (CT vs CC).

Genetics and Molecular Research 15 (3): gmr.15037969 


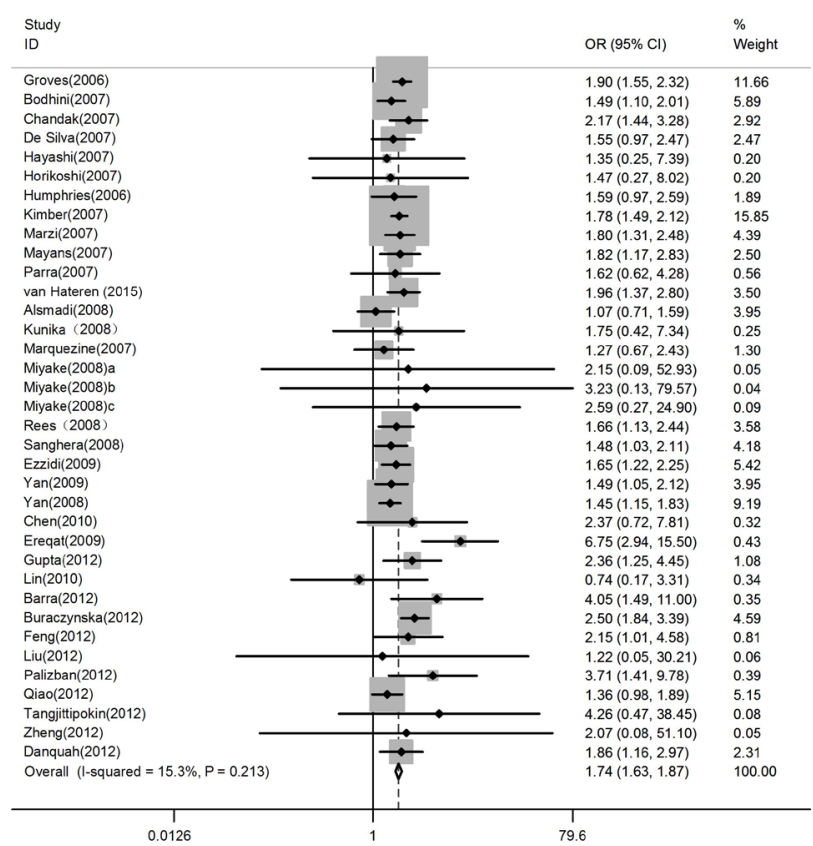

Figure 4. Forest plot showing association between the TCF7L2 rs7903146 polymorphism and T2DM risk under homozygous model (TT vs CC).

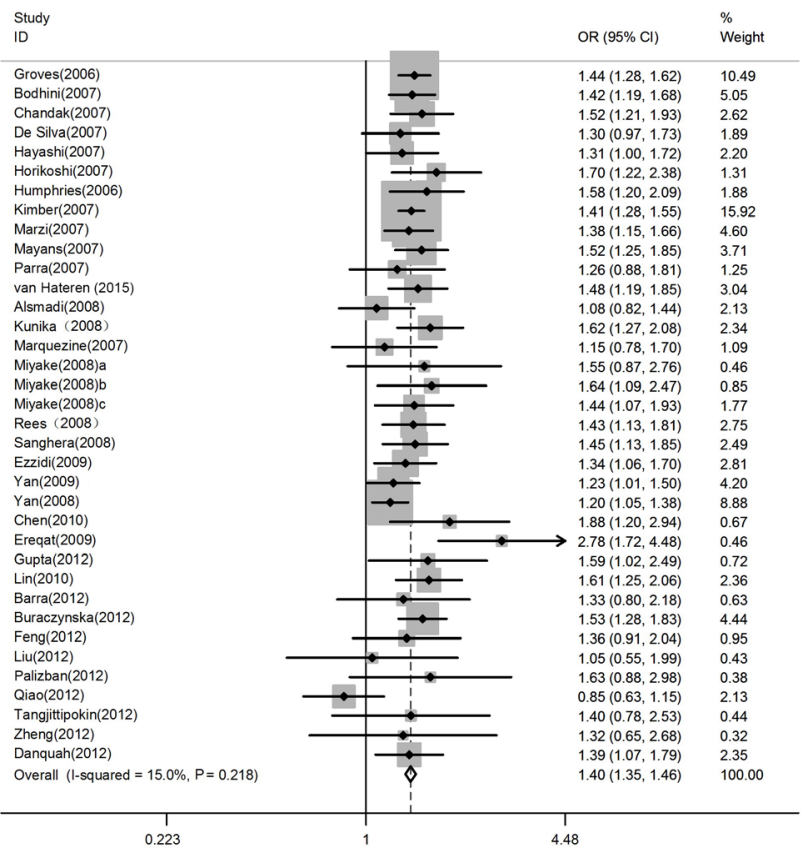

Figure 5. Forest plot showing association between the TCF7L2 rs7903146 polymorphism and T2DM risk under dominant model $(\mathrm{TT}+\mathrm{CT}$ vs $\mathrm{CC})$.

Genetics and Molecular Research 15 (3): gmr.15037969 


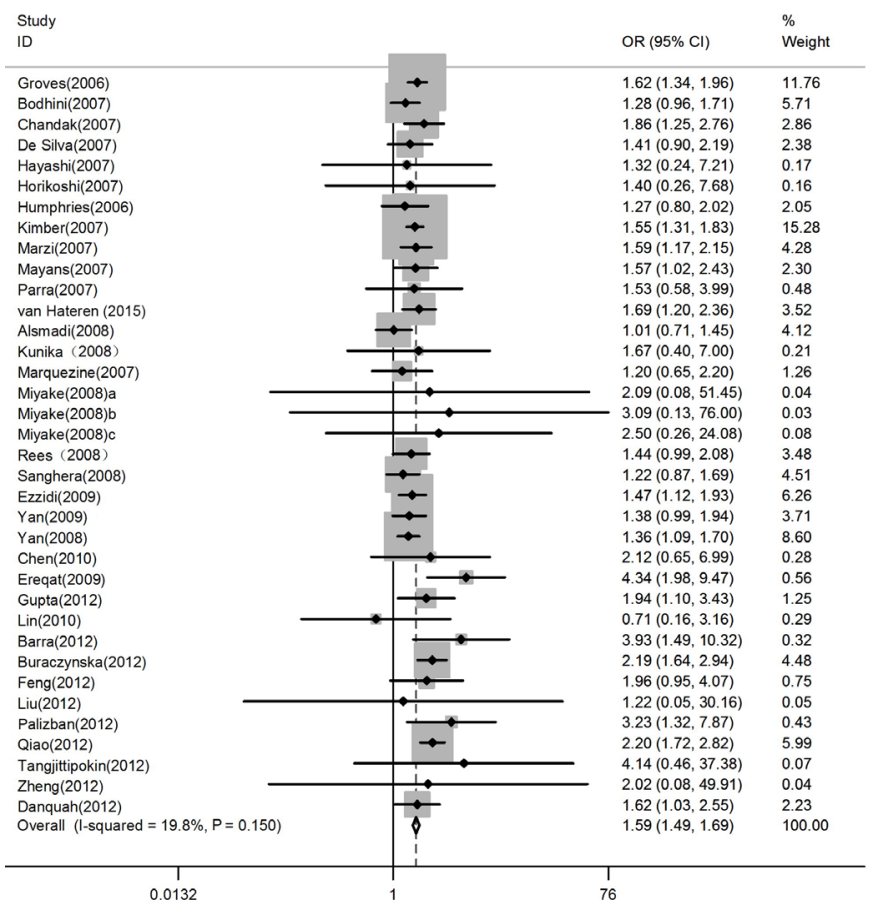

Figure 6. Forest plot showing the association between TCF7L2 rs7903146 polymorphism and T2DM risk under recessive model (TT vs $\mathrm{CT}+\mathrm{CC})$.

Furthermore, the Egger test revealed significant evidence of symmetry $(\mathrm{P}=0.983$ for $\mathrm{CT}$ vs $\mathrm{CC}, \mathrm{P}=0.278$ for $\mathrm{TT}$ vs $\mathrm{CC}, \mathrm{P}=0.520$ for $\mathrm{TT}+\mathrm{CT}$ vs $\mathrm{CC}$, and $\mathrm{P}=0.310$ for TT $v s \mathrm{CT}+\mathrm{CC}$ ).

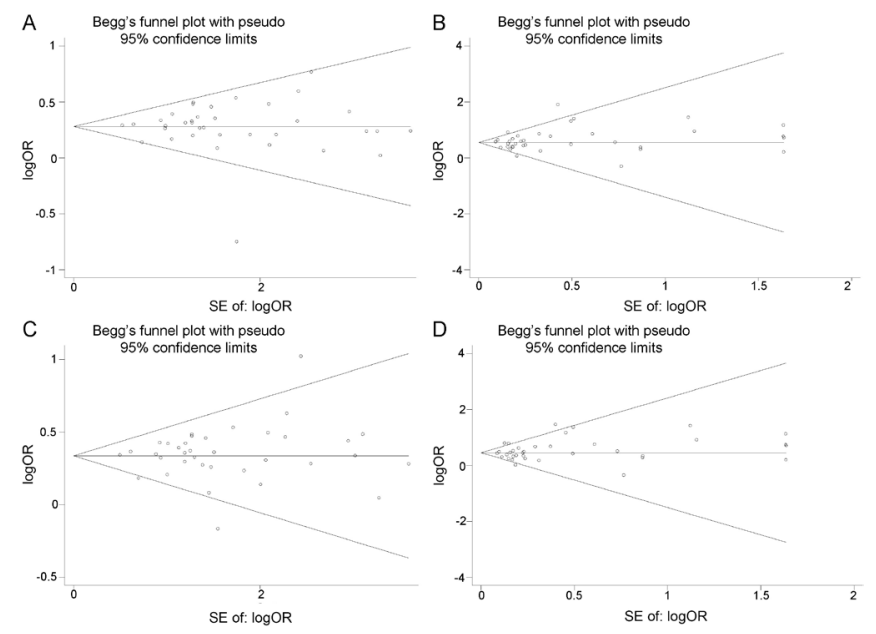

Figure 7. Begg's funnel plot for publication bias test. A. Heterozygous model (CT vs CC); B. homozygous model (TT vs CC); C. dominant model (TT+CT vs CC); and D. recessive model (TT vs $\mathrm{CT}+\mathrm{CC})$.

Genetics and Molecular Research 15 (3): gmr.15037969 


\section{Sensitivity analysis}

To assess the value of individual studies, we conducted sensitivity analysis by omitting one at a time and then calculated the combined OR for the selected studies. No studies deviated from the combined results of the heterozygous model (CT vs CC), homozygous model (TT vs $\mathrm{CC}$ ), dominant model (TT $+\mathrm{CT} v_{s} \mathrm{CC}$ ), and recessive model (TT vs $\mathrm{CT}+\mathrm{CC}$ ) (data not shown), suggesting that the results of our meta-analysis were robust and reliable.

\section{DISCUSSION}

Despite increasing evidence that the TCF7L2 gene is associated with an increased T2DM risk in ethnic groups worldwide (Hayashi et al., 2007; Miyake et al., 2008; Palizban et al., 2012; Uma Jyothi et al., 2013; Wang et al., 2013), some studies presented the opposite conclusion (Chang et al., 2007; Ng et al., 2007; Zheng et al., 2012a). No consistent results have been reported because of the limited sample size and ethnicity heterogeneity in the studies. Based on our comprehensive meta-analysis, the TCF7L2 rs7903146 polymorphism was associated with an enhanced susceptibility to T2DM in the genetic models tested.

However, the exact mechanisms by which $T C F 7 L 2$ increases the risk of T2DM remain unclear. Loos et al. (2007) demonstrated that TCF7L2 polymorphisms increase the risk of T2DM by impairing $\beta$-cell function and modulating proinsulin levels in a British Europid population. TCFL2 encodes a basic helix-loop-helix transcription factor 4 (TCF-4), which acts as a nuclear receptor for the Wnt/ $\beta$-catenin pathway (Smith, 2007), and can preferentially bind to Wnt-responsive elements in genes induced by $\beta$-catenin (Gougelet et al., 2014). It is well known that the $\beta$-catenin/TCF-4 complex participates in various biological events. Particularly, the complex has been found to have a critical role in pancreatic and islet development (Mulholland et al., 2005; Papadopoulou and Edlund, 2005), and thus contributes to T2DM initiation and progression. In addition, Wnt signaling may utilize $\beta$-catenin/TCF-4 to mediate the expression of many target genes such as tumor necrosis factor- $\alpha$, interleukin- $1 \beta$, fibroblast growth factor, and vascular endothelial growth factor (Zhang et al., 2009). Moreover, high levels of tumor necrosis factor- $\alpha$ were correlated with impaired glucose tolerance, defective glucoregulation, and glycated hemoglobin, as well as hyperglycemia and whole-body insulin resistance in T2DM (Daniele et al., 2014; Ellekilde et al., 2014). Individuals with T2DM have significantly increased levels of interleukin- $1 \beta$ compared with healthy individuals (Atieh et al., 2014). A previous study (Yang et al., 2010) demonstrated that the vascular endothelial growth factor polymorphism (rs2010963) was a key risk factor for coronary artery disease susceptibility in $\mathrm{T} 2 \mathrm{DM}$ patients.

The results of our meta-analysis were based on both Asian and Caucasian subjects, including 26,498 T2DM patients and 37,282 control subjects, and demonstrated that the rs7903146 polymorphism was associated with an elevated risk for T2DM under the allelic, heterozygous, homozygous, dominant, and recessive models, which agrees with the original findings. This is the most comprehensive and systematic meta-analysis that has used worldwide populations to explore the association between the TCF7L2 rs7903146 polymorphism and T2DM. Publication bias testing and sensitivity analysis were conducted systematically to validate the reliability and robustness of the meta-analysis. However, potential limitations must be recognized. T2DM is a complex disease resulting from the combined effect of genetic variants and environmental predisposing factors (Brunetti et al., 2014; Chang et al., 2014; Li

Genetics and Molecular Research 15 (3): gmr.15037969 
et al., 2014; Wang et al., 2014; Picos-Cárdenas et al., 2015), which were not systematically assessed in our meta-analysis. Therefore, to increase the power of our conclusions, additional well-designed studies including larger sample sizes are required to reveal the association between genetic variants and T2DM.

\section{Conflicts of interests}

The authors declare no conflict of interest.

\section{REFERENCES}

Alberti KG and Zimmet PZ (1998). Definition, diagnosis and classification of diabetes mellitus and its complications. Part 1: diagnosis and classification of diabetes mellitus provisional report of a WHO consultation. Diabet. Med. 15: 539553. http://dx.doi.org/10.1002/(SICI)1096-9136(199807)15:7<539::AID-DIA668>3.0.CO;2-S

Alsmadi O, Al-Rubeaan K, Mohamed G, Alkayal F, et al. (2008). Weak or no association of TCF7L2 variants with Type 2 diabetes risk in an Arab population. BMC Med. Genet. 9: 72.

Atieh MA, Faggion Jr CM and Seymour GJ (2014). Cytokines in patients with type 2 diabetes and chronic periodontitis: A systematic review and meta-analysis. Diabetes Res. Clin. Pract. 104: e38-e45. http://dx.doi.org/10.1016/j. diabres.2014.02.002

Barra GB, Dutra LA, Watanabe SC, Costa PG, et al. (2012). Association of the rs7903146 single nucleotide polymorphism at the Transcription Factor 7-like 2 (TCF7L2) locus with type 2 diabetes in Brazilian subjects. Arq. Bras. Endocrinol. Metabol. 56: 479-484.

Bodhini D, Radha V, Dhar M, Narayani N, et al. (2007). The rs12255372(G/T) and rs7903146(C/T) polymorphisms of the TCF7L2 gene are associated with type 2 diabetes mellitus in Asian Indians. Metabolism 56: 1174-1178. http://dx.doi. org/10.1016/j.metabol.2007.04.012

Brunetti A, Chiefari E and Foti D (2014). Recent advances in the molecular genetics of type 2 diabetes mellitus. World $J$. Diabetes 5: 128-140.

Buraczynska M, Zukowski P, Wacinski P, Berger-Smyka B, et al. (2012). Hemotactic cytokine receptor 5 gene polymorphism: relevance to microvascular complications in type 2 diabetes. Cytokine 58: 213-217.

Cauchi S and Froguel P (2008). TCF7L2 genetic defect and type 2 diabetes. Curr. Diab. Rep. 8: 149-155. http://dx.doi. org/10.1007/s11892-008-0026-x

Chandak GR, Janipalli CS, Bhaskar S, Kulkarni SR, et al. (2007). Common variants in the TCF7L2 gene are strongly associated with type 2 diabetes mellitus in the Indian population. Diabetologia 50: 63-67.

Chang YC, Chang TJ, Jiang YD, Kuo SS, et al. (2007). Association study of the genetic polymorphisms of the transcription factor 7-like 2 (TCF7L2) gene and type 2 diabetes in the Chinese population. Diabetes 56: 2631-2637. http://dx.doi. org/10.2337/db07-0421

Chang YC, Liu PH, Yu YH, Kuo SS, et al. (2014). Validation of type 2 diabetes risk variants identified by genome-wide association studies in Han Chinese population: a replication study and meta-analysis. PLoS One 9: e95045. http:// dx.doi.org/10.1371/journal.pone.0095045

Chen Z, Zhang X, Ma G, Qian Q, et al. (2010). Association study of four variants in KCNQ1 with type 2 diabetes mellitus and premature coronary artery disease in a Chinese population. Mol. Biol. Rep. 37: 207-212.

da Costa BR, Cevallos M, Altman DG, Rutjes AW, et al. (2011). Uses and misuses of the STROBE statement: bibliographic study. BMJ Open 1: e000048. http://dx.doi.org/10.1136/bmjopen-2010-000048

Daniele G, Guardado Mendoza R, Winnier D, Fiorentino TV, et al. (2014). The inflammatory status score including IL-6, TNF- $\alpha$, osteopontin, fractalkine, MCP-1 and adiponectin underlies whole-body insulin resistance and hyperglycemia in type 2 diabetes mellitus. Acta Diabetol. 51: 123-131. http://dx.doi.org/10.1007/s00592-013-0543-1

Danquah I, Bedu-Addo G, Terpe KJ, Micah F, et al. (2012). Diabetes mellitus type 2 in urban Ghana: characteristics and associated factors. BMC Public. Health 12: 210.

De Silva NM, Steele A, Shields B, Knight B, et al. (2007). The transcription factor 7-like 2 (TCF7L2) gene is associated with Type 2 diabetes in UK community-based cases, but the risk allele frequency is reduced compared with UK cases selected for genetic studies. Diabet. Med. 24: 1067-1072.

Ellekilde M, Krych L, Hansen CH, Hufeldt MR, et al. (2014). Characterization of the gut microbiota in leptin deficient obese mice - Correlation to inflammatory and diabetic parameters. Res. Vet. Sci. 96: 241-250. http://dx.doi. org/10.1016/j.rvsc.2014.01.007

Genetics and Molecular Research 15 (3): gmr.15037969 
Ereqat S, Nasereddin A, Cauchi S, Azmi K, et al. (2009). Association of a common variant in TCF7L2 gene with type 2 diabetes mellitus in the Palestinian population. Acta Diabetol. 47 (Suppl 1): 195-198.

Ezzidi I, Mtiraoui N, Kacem M, Chaieb M, et al. (2009). Identification of specific angiotensin-converting enzyme variants and haplotypes that confer risk and protection against type 2 diabetic nephropathy. Diabetes Metab. Res. Rev. 25: 717-724.

Feng Y, Yang Y, Ma X, Chen K, et al. (2012). Prevalence of diabetes among Han, Manchu and Korean ethnicities in the Mudanjiang area of China: a cross-sectional survey. BMC Public. Health 12: 23.

Gougelet A, Torre C, Veber P, Sartor C, et al. (2014). T-cell factor 4 and $\beta$-catenin chromatin occupancies pattern zonal liver metabolism in mice. Hepatology 59: 2344-2357.http://dx.doi.org/10.1002/hep.26924

Grant SF, Thorleifsson G, Reynisdottir I, Benediktsson R, et al. (2006). Variant of transcription factor 7-like 2 (TCF7L2) gene confers risk of type 2 diabetes. Nat. Genet. 38: 320-323. http://dx.doi.org/10.1038/ng1732

Groves CJ, Zeggini E, Minton J, Frayling TM, et al. (2006). Association analysis of 6,736 U.K. subjects provides replication and confirms TCF7L2 as a type 2 diabetes susceptibility gene with a substantial effect on individual risk. Diabetes 55: 2640-2644

Gupta R, Guptha S, Gupta VP, Agrawal A, et al. (2012). Twenty-year trends in cardiovascular risk factors in India and influence of educational status. Eur. J. Prev. Cardiol. 19: 1258-1271.

Harbord RM, Egger M and Sterne JA (2006). A modified test for small-study effects in meta-analyses of controlled trials with binary endpoints. Stat. Med. 25: 3443-3457. http://dx.doi.org/10.1002/sim.2380

Hayashi T, Iwamoto Y, Kaku K, Hirose H, et al. (2007). Replication study for the association of TCF7L2 with susceptibility to type 2 diabetes in a Japanese population. Diabetologia 50: 980-984. http://dx.doi.org/10.1007/s00125-007-0618-Z

Horikoshi M, Hara K, Ito C, Nagai R, et al. (2007). A genetic variation of the transcription factor 7-like 2 gene is associated with risk of type 2 diabetes in the Japanese population. Diabetologia 50: 747-751.

Humphries SE, Cooper JA, Talmud PJ and Miller GJ (2007). Candidate gene genotypes, along with conventional risk factor assessment, improve estimation of coronary heart disease risk in healthy UK men. Clin. Chem. 53: 8-16. http:// dx.doi.org/10.1373/clinchem.2006.074591

Kimber CH, Doney AS, Pearson ER, McCarthy MI, et al. (2007). TCF7L2 in the Go-DARTS study: evidence for a gene dose effect on both diabetes susceptibility and control of glucose levels. Diabetologia 50: 1186-1191.

Kunika K, Tanahashi T, Numata S, Ueno S, et al. (2008). Common coding variant in the TCF7L2 gene and study of the association with type 2 diabetes in Japanese subjects. J. Hum. Genet. 53: 972-982.

Li L, Gao K, Zhao J, Feng T, et al. (2014). Glucagon gene polymorphism modifies the effects of smoking and physical activity on risk of type 2 diabetes mellitus in Han Chinese. Gene 534: 352-355. http://dx.doi.org/10.1016/j. gene.2013.09.121

Lin JD, Hsia TL, Wu CZ, Su CC, et al. (2010). The first and second phase of insulin secretion in naive Chinese type 2 diabetes mellitus. Metabolism 59: 780-786.

Ling W, Farrell M and Ali R (2004). Cochrane systematic reviews: time for an introduction and appraisal. Drug Alcohol Depend. 73: 217-218. http://dx.doi.org/10.1016/j.drugalcdep.2003.11.003

Liu J, Liu J, Tian LM, Liu JX, et al. (2012). Association of ghrelin Leu72Met polymorphism with type 2 diabetes mellitus in Chinese population. Gene 504: 309-312.

Loos RJ, Franks PW, Francis RW, Barroso I, et al. (2007). TCF7L2 polymorphisms modulate proinsulin levels and betacell function in a British Europid population. Diabetes 56: 1943-1947. http://dx.doi.org/10.2337/db07-0055

Mantel N and Haenszel W (1959). Statistical aspects of the analysis of data from retrospective studies of disease. J. Natl. Cancer Inst. 22: 719-748.

Marquezine GF, Oliveira CM, Pereira AC, Krieger JE, et al. (2007). Metabolic syndrome determinants in an urban population from Brazil: social class and gender-specific interaction. Int. J. Cardiol. 129: 259-265.

Marzi C, Huth C, Kolz M, Grallert H, et al. (2007). Variants of the transcription factor 7-like 2 gene (TCF7L2) are strongly associated with type 2 diabetes but not with the metabolic syndrome in the MONICA/KORA surveys. Horm. Metab. Res. 39: 46-52.

Mayans S, Lackovic K, Lindgren P, Ruikka K, et al. (2007). TCF7L2 polymorphisms are associated with type 2 diabetes in northern Sweden. Eur. J. Hum. Genet. 15: 342-346.

Midgette AS, Wong JB, Beshansky JR, Porath A, et al. (1994). Cost-effectiveness of streptokinase for acute myocardial infarction: A combined meta-analysis and decision analysis of the effects of infarct location and of likelihood of infarction. Med. Decis. Making 14: 108-117.http://dx.doi.org/10.1177/0272989X9401400203

Miyake K, Mita M, Zenibayashi M, Hirota Y, et al. (2008a). Association study of the effect of WFS1 polymorphisms on risk of type 2 diabetes in Japanese population. Kobe. J. Med. Sci. 54: E192-199.

Miyake K, Horikawa Y, Hara K, Yasuda K, et al. (2008b). Association of TCF7L2 polymorphisms with susceptibility to type 2 diabetes in 4,087 Japanese subjects. J. Hum. Genet. 53: 174-180. http://dx.doi.org/10.1007/s10038-007-0231-5

Genetics and Molecular Research 15 (3): gmr.15037969 
Miyake K, Zenibayashi M, Horikawa Y, Hirota Y, et al. (2008c). Lack of association of LRP5 and LRP6 polymorphisms with type 2 diabetes mellitus in the Japanese population. Endocr. J. 55: 699-707.

Mulholland DJ, Dedhar S, Coetzee GA and Nelson CC (2005). Interaction of nuclear receptors with the Wnt/beta-catenin/ Tcf signaling axis: Wnt you like to know? Endocr. Rev. 26: 898-915.http://dx.doi.org/10.1210/er.2003-0034

$\mathrm{Ng} \mathrm{MC}$, Tam CH, Lam VK, So WY, et al. (2007). Replication and identification of novel variants at TCF7L2 associated with type 2 diabetes in Hong Kong Chinese. J. Clin. Endocrinol. Metab. 92: 3733-3737. http://dx.doi.org/10.1210/ jc. 2007-0849

Pagán A, Sabater-Molina M, Olza J, Prieto-Sánchez MT, et al. (2014). A gene variant in the transcription factor 7-like 2 (TCF7L2) is associated with an increased risk of gestational diabetes mellitus. Eur. J. Obstet. Gynecol. Reprod. Biol. 180: 77-82. http://dx.doi.org/10.1016/j.ejogrb.2014.06.024

Palizban A, Nikpour M, Salehi R and Maracy MR (2012). Association of a common variant in TCF7L2 gene with type 2 diabetes mellitus in a Persian population. Clin. Exp. Med. 12: 115-119. http://dx.doi.org/10.1007/s10238-011-0144-7

Papadopoulou S and Edlund H (2005). Attenuated Wnt signaling perturbs pancreatic growth but not pancreatic function. Diabetes 54: 2844-2851.http://dx.doi.org/10.2337/diabetes.54.10.2844

Parra EJ, Cameron E, Simmonds L, Valladares A, et al. (2007). Association of TCF7L2 polymorphisms with type 2 diabetes in Mexico City. Clin. Genet. 71: 359-566.

Picos-Cárdenas VJ, Sáinz-González E, Miliar-García A, Romero-Zazueta A, et al. (2015). Calpain-10 gene polymorphisms and risk of type 2 diabetes mellitus in Mexican mestizos. Genet. Mol. Res. 14: 2205-2215. http://dx.doi. org/10.4238/2015.March.27.6

Qiao H, Zhang X, Zhao X, Zhao Y, et al. (2012). Genetic variants of TCF7L2 are associated with type 2 diabetes in a northeastern Chinese population. Gene 495: 115-119.

Rees SD, Bellary S, Britten AC, O'Hare JP, et al. (2008). Common variants of the TCF7L2 gene are associated with increased risk of type 2 diabetes mellitus in a UK-resident South Asian population. BMC Med. Genet. 9: 8.

Ren Q, Han XY, Wang F, Zhang XY, et al. (2008). Exon sequencing and association analysis of polymorphisms in TCF7L2 with type 2 diabetes in a Chinese population. Diabetologia 51: 1146-1152. http://dx.doi.org/10.1007/s00125-0081039-3

Risérus U, Willett WC and Hu FB (2009). Dietary fats and prevention of type 2 diabetes. Prog. Lipid Res. 48: 44-51. http:// dx.doi.org/10.1016/j.plipres.2008.10.002

Sanghera DK, Nath SK, Ortega L, Gambarelli M, et al. (2008). TCF7L2 polymorphisms are associated with type 2 diabetes in Khatri Sikhs from North India: genetic variation affects lipid levels. Ann. Hum. Genet. 72: 499-509.

Saxena R, Gianniny L, Burtt NP, Lyssenko V, et al. (2006). Common single nucleotide polymorphisms in TCF7L2 are reproducibly associated with type 2 diabetes and reduce the insulin response to glucose in nondiabetic individuals. Diabetes 55: 2890-2895.http://dx.doi.org/10.2337/db06-0381

Smith U (2007). TCF7L2 and type 2 diabetes - we WNT to know. Diabetologia 50: 5-7. http://dx.doi.org/10.1007/s00125006-0521-Z

Sun L, Liu JY and Li LR (2015). Serum YKL-40 levels are associated with type 2 diabetes mellitus in patients with obstructive sleep apnea syndrome. Genet. Mol. Res. 14: 8919-8925.http://dx.doi.org/10.4238/2015.August.3.15

Tangjittipokin W, Chongjarean N, Plengvidhya N, Homsanit M, et al. (2012). Transcription factor 7-like 2 (TCF7L2) variations associated with earlier age-onset of type 2 diabetes in Thai patients. J. Genet. 91: 251-255.

Uma Jyothi K, Jayaraj M, Subburaj KS, Prasad KJ, et al. (2013). Association of TCF7L2 gene polymorphisms with T2DM in the population of Hyderabad, India. PLoS One 8: e60212. http://dx.doi.org/10.1371/journal.pone.0060212

van Hateren KJ, Landman GW, Groenier KH, Bilo HJ, et al. (2015). Effectiveness of angiotensin II receptor antagonists in a cohort of Dutch patients with type 2 diabetes mellitus (ZODIAC-14). Can. J. Diabetes 39: 157-161.

Wagner R, Staiger H, Ullrich S, Stefan N, et al. (2014). Untangling the interplay of genetic and metabolic influences on beta-cell function: Examples of potential therapeutic implications involving TCF7L2 and FFAR1. Mol. Metab. 3: 261-267. http://dx.doi.org/10.1016/j.molmet.2014.01.001

Wang W, Xie Z, Lin Y and Zhang D (2014). Association of inorganic arsenic exposure with type 2 diabetes mellitus: a meta-analysis. J. Epidemiol. Community Health 68: 176-184. http://dx.doi.org/10.1136/jech-2013-203114

Wang YP, Wang WJ, Sheng TX, Cui ZW, et al. (2013). [Study of the association between SNP rs7903146(C/T) in TCF7L2 and metabolic syndrome in Chinese Korean and Han populations from Yanbian]. Zhonghua Yi Xue Yi Chuan Xue Za Zhi 30: 467-472.

Wu SL (2015). Staging of type 2 diabetes mellitus. Genet. Mol. Res. 14: 2118-2121. http://dx.doi.org/10.4238/2015. March.20.22

Xia Q, Deliard S, Yuan CX, Johnson ME, et al. (2015). Characterization of the transcriptional machinery bound across the widely presumed type 2 diabetes causal variant, rs7903146, within TCF7L2. Eur. J. Hum. Genet. 23: 103-109. http:// dx.doi.org/10.1038/ejhg.2014.48

Genetics and Molecular Research 15 (3): gmr.15037969 
Yan J, Tie G, Park B, Yan Y, et al. (2009). Recovery from hind limb ischemia is less effective in type 2 than in type 1 diabetic mice: roles of endothelial nitric oxide synthase and endothelial progenitor cells. J. Vasc. Surg. 50: 14121422 .

Yan Y, North KE, Ballantyne CM, Brancati FL, et al. (2008). Transcription factor 7-like 2 (TCF7L2) polymorphism and context-specific risk of type 2 diabetes in African American and Caucasian adults: the Atherosclerosis Risk in Communities study. Diabetes 58: 285-289.

Yang Y, Andresen BT, Yang K, Zhang Y, et al. (2010). Association of vascular endothelial growth factor $-634 \mathrm{C} / \mathrm{G}$ polymorphism and diabetic retinopathy in type 2 diabetic Han Chinese. Exp. Biol. Med. (Maywood) 235: 1204-1211. http://dx.doi.org/10.1258/ebm.2010.010102

Yu M, Xu XJ, Yin JY, Wu J, et al. (2010). KCNJ11 Lys23Glu and TCF7L2 rs290487(C/T) polymorphisms affect therapeutic efficacy of repaglinide in Chinese patients with type 2 diabetes. Clin. Pharmacol. Ther. 87: 330-335. http://dx.doi. org/10.1038/clpt.2009.242

Zhang DL, Gu LJ, Liu L, Wang CY, et al. (2009). Effect of Wnt signaling pathway on wound healing. Biochem. Biophys. Res. Commun. 378: 149-151. http://dx.doi.org/10.1016/j.bbrc.2008.11.011

Zheng X, Ren W, Zhang S, Liu J, et al. (2012a). Association of type 2 diabetes susceptibility genes (TCF7L2, SLC30A8, PCSK1 and PCSK2) and proinsulin conversion in a Chinese population. Mol. Biol. Rep. 39: 17-23. http://dx.doi. org/10.1007/s11033-011-0705-6

Zheng YY, Xie X, Ma YT, Yang YN, et al. (2012b). Relationship between type 2 diabetes mellitus and a novel polymorphism C698T in C5L2 in the Chinese Han population. Endocrine 41: 296-301.

Genetics and Molecular Research 15 (3): gmr.15037969 